\title{
The Phylogeny of the Cetartiodactyla Based on Complete Mitochondrial Genomes
}

\author{
Qin Wang ${ }^{1} \&$ Chengzhong Yang ${ }^{2}$ \\ ${ }^{1}$ Department of Biology, College of Life Sciences, Sichuan Agricultural University, Yaan, P. R. China \\ ${ }^{2}$ School of Life Sciences, Jinggangshan University, Ji'an, Jiangxi, P. R. China \\ Correspondence: Chengzhong Yang, School of Life Sciences, Jinggangshan University, Ji'an, Jiangxi 343009, P. \\ R. China. E-mail: chzhongyang@gmail.com
}

Received: November 23, 2011 Accepted: April 15, 2013 Online Published: May 15, 2013

doi:10.5539/ijb.v5n3p30

URL: http://dx.doi.org/10.5539/ijb.v5n3p30

\begin{abstract}
Efforts have been made to investigate the phylogeny of Cetartiodactyla; however, the relationships within this group still remain controversial. Due to the limitation of collecting samples from some key species of the Cetartiodactyla, it is difficult to perform molecular phylogenetic analysis to find out their precise classification scheme. Fortunately, much up-to-date, more molecular data samples of this group are available from GenBank. To further clarify the relationships within the Cetartiodactyla, phylogenetic analyses of the Cetartiodactyla were conducted using Bayesian and maximum likelihood (ML) methods based on complete mitochondrial genomes. The results indicate that Moschidae sister to Bovidae, and recognize the families Moschidae, Bovidae, Cervidae and Giraffidae to be four monophyletic groups. Phylogenetic trees also indicate that the basal divergence within the Cetartiodactyla is between the Suina and a strongly supported clade of the remaining Cetartiodactyla; Tragulidae is the early offshoot within the Ruminantia, followed by the Antilocapridae.
\end{abstract}

Keywords: molecular phylogeny, cetartiodactyla, mitochondrial genome

\section{Introduction}

Over the last 150 years, Artiodactyla has been regarded as a single origin and was usually classified into three main suborders: Ruminantia, Tylopoda, and Suiformes (Simpson, 1945). Recent works suggest a close relationship between Artiodactyla and Cetacea based on a host of paleontological (Thewissen \& Hussain, 1993), morphological (Thewissen et al., 2001), and molecular (Murphy et al., 2001; Hassanin et al., 2012) studies. Concurrently, molecular data analyses designate that the Cetacea sister to Hippopotamidae (Murphy et al., 2001; Nikaido et al., 1999), which contradicted with the traditional monophyly of Artiodactyla and suggested to put all species of Artiodactyla and Cetacea into a single order, called Cetartiodactyla (Montgelard et al., 1997). Forefore, Cetartiodactyla comprises of all the species from Cetacea, Hippopotamidae, Antilocapridae, Bovidae, Cervidae, Giraffidae, Moschidae, Tragulidae, Suidae, Tayassuidae and Camelidae. However, phylogenetic relationships of Cetartiodactyla still remain ambiguous. For instance, the issue about what is the root of Cetartiodactyla is unresolved (Gatesy et al., 2002; Ursing et al., 2000). And historically, there were three hypotheses: a basal position for the Suina (Matthee et al., 2001) or Tylopoda (Gatesy et al., 1999; Zhou et al., 2011) or a paraphyly of Tylopoda and Suina (Arnason et al., 2000) as a sister group to Cetruminantia (Ruminantia + Cetacea + Hippopotamidae). Although Tylopoda hypothesis was favoured by most molecular studies (Nikaido et al., 1999; Agnarsson \& May-Collado, 2008; Murphy et al., 2001), it was not proven perfect by rigorous statistical testing in most cases (Shimodaira et al., 2002). And these studies did not reject the other two alternative topologies at a significant statistical level (Ursing et al., 2000). Moreover, though the Tylopoda hypothesis was widely accepted, Bayesian inference methods dependent on cytochrome b sequences, suggested a sister group relationship between Suina and Ruminantia (Agnarsson \& May-Collado, 2008). Even though supertree analyses, utilizing the supermatrix with maximum parsimony (MRP) (Ragan, 1992), can present respective results of these hypotheses, such conclusions can usually reach no consensus among phylogeny studies (Beck et al., 2006; Gatesy et al., 2002; Price et al., 2005). For instance, Gatesy et al. (2002) suggested Tylopoda and Suina as the earliest diverged group, but Price et al. (2005) determined an early divergence of Tylopoda with additional taxon sampling.

The place of Moschidae (musk deer) within Ruminantia is controversial. Although Moschidae is widely recognized as a monophyletic family (Flerov, 1952; Janis \& Scott, 1988; Li et al., 1998), the interrelationships 
and the phylogenetic position among Ruminantia families are cause for long-standing disputes. Phylogenetic relationships among Cervidae, Moschidae and Bovidae have been investigated using both mitochondrial and nuclear sequences (Su et al., 2001; Matthee et al., 2001; Guha et al., 2007). However, these studies have not conclusively resolved the phylogenetic position of Moschidae. Here, we conducted phylogenetic analyses within Cetartiodactyla based on complete mitochondrial genomes, which will improve our understanding of evolution biology of this mammal group.

\section{Methods}

In this study, all of the complete mitochondrial genomes were downloaded from GenBank, and the 12 heave-strand encoded protein-coding genes were aligned according to Nikaido et al. (2001). After deletion of gaps and ambiguous sites adjacent to gaps, 10,761 nucleotides were obtained. Multiple alignments of the 12 concatenated protein-coding genes of 50 species (Table 1) were performed using ClustalX (Tompson et al., 1997) with the default setting. Two species of Perissodactyla were used to root the tree of Cetartiodactyla (Table 1). Bayesian phylogenetic analysis (BI) was conducted using MrBayes 3.1.2 (Ronquist \& Huelsenbeck, 2003). The best-fit model $(\mathrm{GTR}+\mathrm{I}+\mathrm{G})$ of sequence evolution for Bayesian analyses was obtained by Modeltest 3.7 (Posada \& Crandall, 1998) under the Akaike Information Criterion (AIC). Four independent Markov chains Monte Carlo (MCMC) ran simultaneously for ten million generations, sampling one tree per 200 generations, and discarding the first $25 \%$ of samples as the burn-in. Tracer v1.3 (Rambaut \& Drummond, 2005) was used to check chain convergence and parameter mixing. Maximum likelihood (ML) analyses were performed in RAxML Web-Servers (Stamatakis et al., 2008) using default parameters with 1000 bootstraps replicates.

Table 1. The sequence's accession number of the fifty species used for phylogenetic analyses

\begin{tabular}{lll}
\hline Species & Family & GenBank No. \\
\hline Balaenoptera musculus & Balaenopteridae & NC_001601 \\
Caperea marginata & Neobalaenidae & AP006475 \\
Balaena mysticetus & Balaenidae & AP006472 \\
Lipotes vexillifer & Lipotidae & NC_007629 \\
Physeter catodon & Physeteridae & NC_002503 \\
Hippopotamus amphibius & Hippopotamidae & AP003425 \\
Antilocapra americana & Antilocapridae & JN632597 \\
Tragulus kanchil & Tragulidae & JN632709 \\
Hyemoschus aquaticus & Tragulidae & JN632650 \\
Aepyceros melampus & Bovidae & JN632592 \\
Connochaetes taurinus & Bovidae & JN632627 \\
Alcelaphus buselaphus & Bovidae & JN632594 \\
Sylvicapra grimmia & Bovidae & JN632701 \\
Philantomba monticola & Bovidae & JN632687 \\
Oryx dammah & Bovidae & JN632677 \\
Hippotragus equinus & Bovidae & JN632647 \\
Pelea capreolus & Bovidae & JN632684 \\
Kobus ellipsiprymnus & Bovidae & JN632651 \\
Redunca arundinum & Bovidae & JN632694 \\
Bison bonasus & Bovidae & NC_014044 \\
Bos indicus & Bovidae & NC_005971 \\
Bos grunniens & Bovidae & NC_006380 \\
Procapra przewalskii & Bovidae & NC_014875 \\
Antilope cervicapra & Bovidae & NC_012098 \\
\hline & & \\
\hline & &
\end{tabular}




\begin{tabular}{|c|c|c|}
\hline Pantholops hodgsonii & Bovidae & NC_007441 \\
\hline Ammotragus lervia & Bovidae & NC_009510 \\
\hline Ovis aries & Bovidae & NC_001941 \\
\hline Budorcas taxicolor & Bovidae & NC_013069 \\
\hline Muntiacus muntjak & Cervidae & NC_004563 \\
\hline Muntiacus crinifrons & Cervidae & NC_004577 \\
\hline Muntiacus reevesi & Cervidae & NC_004069 \\
\hline Elaphodus cephalophus & Cervidae & NC_008749 \\
\hline Cervus nippon yesoensis & Cervidae & NC_006973 \\
\hline Cervus eldi & Cervidae & NC_014701 \\
\hline Rusa unicolor swinhoei & Cervidae & NC_008414 \\
\hline Cervus elaphus yarkandensis & Cervidae & NC_013840 \\
\hline Rangifer tarandus & Cervidae & NC_007703 \\
\hline Hydropotes inermis & Cervidae & EU315254 \\
\hline Giraffa camelopardalis & Giraffidae & AP003424 \\
\hline Okapia johnstoni & Giraffidae & JN632674 \\
\hline Moschus berezovskii & Moschidae & NC_012694 \\
\hline Moschus moschiferus & Moschidae & NC_013753 \\
\hline Moschus chrysogaster & Moschidae & JQ608470 \\
\hline Sus scrofa & Suidae & AJ002189 \\
\hline Tayassu tajacu & Tayassuidae & AP003427 \\
\hline Camelus dromedarius & Camelidae & NC_009849 \\
\hline Camelus ferus & Camelidae & NC_009629 \\
\hline Lama glama & Camelidae & AP003426 \\
\hline Equus asinus (out-group) & Equidae & NC_001788 \\
\hline Equus caballus (out-group) & Equidae & NC 001640 \\
\hline
\end{tabular}

\section{Results}

Phylogenetic trees of Cetartiodactyla, constructed using BI and ML methods, show a similar topology (Figure 1). The initial clade in Cetartiodactyla is between Suina and Hippopotamidae/Cetaceae/Ruminantia lineages with a strongly supported rate $(\mathrm{PP}=1.0, \mathrm{BS}=73$ ) (Figure 1). Then, Tylopoda, Whippomorpha and Ruminantia form separate successive branches. All members of Ruminantia cluster together, with the Tragulidae separate from the other families. Within the Pecora, the Antilocapridae is the early offshoot, and the families Bovidae, Cervidae, Moschidae and Giraffidae were monophyletic. The Bovidae, Cervidae and Moschidae form a clade which is a sister group to the Giraffidae. Moschidae is the sister group of Bovidae, both of them form a clade which clusters with Cervidae. Our results present that the association of Hippopotamidae and Cetacea, formed Whippomorpha within Artiodactyla $(\mathrm{PP}=1.0, \mathrm{BS}=100)$. 


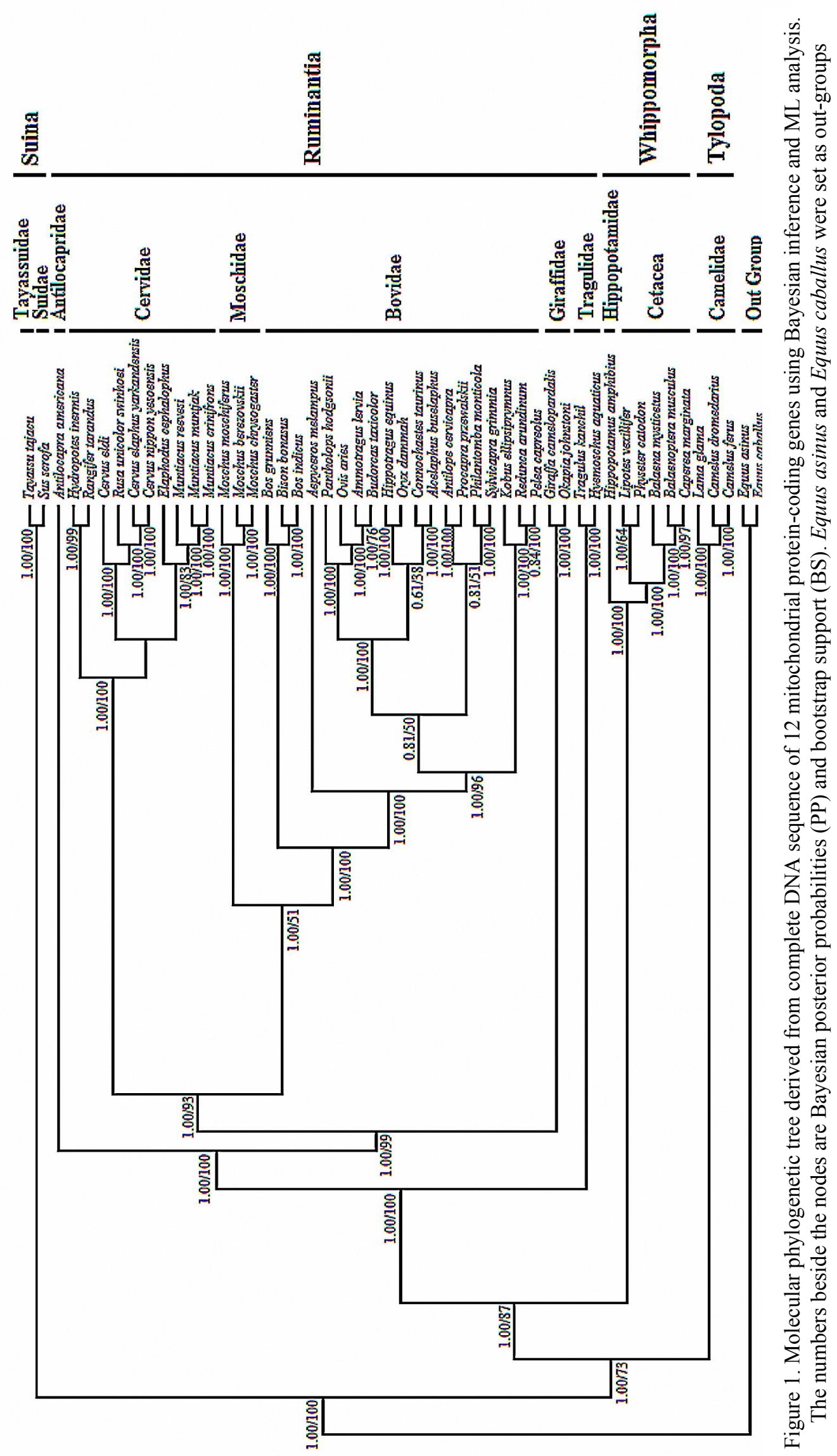




\section{Discussion}

During the last two decades, extensive efforts have been made to investigate phylogenetic relationships of Cetartiodactyla (e.g., O'Leary \& Gatesy, 2008; Gatesy et al., 1999). However, relationships within this group remain unclear. One possibility is that different molecular marker has different evolutionary rate; even if the same maker, the substitution rate varies among taxa. Thus, a single gene or a short DNA sequence applying to phylogeny reconstruction is highly like to produce an incorrect tree topology for a systematic bias and/or long-branch attraction (Nikaido et al., 1999). The complete mitochondrial genome provides a higher level of support for molecular systematics than those based on individual or partial mitochondrial genes (Castro \& Dowton, 2005; Krzywinski et al., 2006). Mitochondrial DNA, especially encoding proteins, such as 12S rDNA, $16 \mathrm{~S}$ rDNA, Cyt $\mathrm{b}$ and ND4, have been frequently utilized as powerful tool for evolutionary studies of animals (Boore \& Brown, 1998). In the present study, it demonstrates that the phylogenetic analyses based on complete mitochondrial genomes can well resolve the high-level relationships within Cetartiodactyla.

The issue about which taxon is basal within the Cetartiodactyla has been intensively debated and remains controversial. And three hypotheses have been proposed: Camelidae, Suidae, or Cetacea. The results of the present study are well-supported in presenting that Artiodactyla is non-monophyletic status on account of its containing Cetacea which is the sister to Hippopotamidae. These findings are also consistent with the previous studies (Murphy et al., 2001; Nikaido et al., 1999; Gatesy et al., 2002; O’Leary \& Gatesy, 2008; Hassanin et al., 2012). The present study indicates that the basal divergence within Cetartiodactyla is between Suina and a strongly supported clade of the remaining Cetartiodactyla ( $\mathrm{PP}=1.0, \mathrm{BS}=73$ ) (Matthee et al., 2001; Hassanin et al., 2012).

The present study unambiguously supports the basal position of the Tragulidae relative to the Pecora families with strong statistical support $(\mathrm{PP}=1.0, \mathrm{BS}=100)$, which is consistent with the previous molecular, morphological and palaeontological evidences (Matthee et al., 2001; Price et al., 2005; Hassanin et al., 2012; Métais et al., 2007).

The position of Moschidae (musk deer) existed of disputed status within the Ruminantia. Historically, the clade has always been difficult to place. It was not until recently that Moschidae were even recognized as a separate family shifting from cervids (Corbert \& Hill, 1980; Leinders \& Heintz, 1980); they are now typically held to cluster with cervids and/or the bovids (Peng et al., 2009; Yang et al., 2012; Hassanin et al., 2012). Here, Moschidae is recognized as a sister group to Bovidae, and the data show Moschidae, Bovidae, Cervidae and Giraffidae to be four monophyletic groups, agreeing with the previous view that placed the Moschidae as a monophyletic family (Flerov, 1952; Janis \& Scott, 1988; Li et al., 1998; Peng et al., 2009).

The molecular evidence for studies of the phylogeny in the Cetartiodactyla were restricted regarding under-representation of taxa or on the basis of partial mitochondrial sequences or on a single gene (Su et al., 2001; Matthee et al., 2001; Guha et al., 2007). Studies of this kind may sometimes be deviate from the phylogenetic accuracy (Agnarsson \& May-Collado, 2008), and this might lead to inconsistencies among different studies. In the present study, the amount of sequence data has provided a reasonable basis for examining the mitogenomic relationships within Cetartiodactyla. However, we are aware that though using mitogenomic datasets to reconstruct the phylogenetic tree of Cetartiodactyla acquired high support values, they can also be systematically biased (Fisher-Reid \& Wiens, 2011). Therefore, to unambiguously resolve phylogenetic relationships within Cetartiodactyla, more complete mitochondrial genomes as well as multiple nuclear markers are needed for future studies.

\section{References}

Agnarsson, I., \& May-Collado, L. J. (2008). The phylogeny of Cetartiodactyla: the importance of dense taxon sampling, missing data, and the remarkable promise of cytochrome $b$ to provide reliable species-level phylogenies. Molecular Phylogenetics and Evolution, 48, 964-985. http://dx.doi.org/10.1016/j.ympev.2008.05.046

Arnason, U., Gullberg, A., Gretarsdottir, S., Ursing, B., \& Janke, A. (2000). The mitochondrial genome of the sperm whale and a new molecular reference for estimating eutherian divergence dates. Journal of Molecular Evolution, 50, 569-578. http://dx.doi.org/10.1007/s002390010060

Beck, R. M., Bininda-Emonds, O. R. P., Cardillo, M., Liu, F. G., \& Purvis, A. (2006). A higherlevel MRP supertree of placental mammals. BMC Evolutionary Biology, 6, 93. http://dx.doi.org/10.1186/1471-2148-6-93

Boore, J. L., \& Brown, W. M. (1998). Big trees from little genomes: Mitochondrial gene order as a phylogenetic 
tool. Current Opinion in Genetics \& Development, 8, 668-674. http://dx.doi.org/10.1016/S0959-437X(98)80035-X

Castro, L. R., \& Dowton, M. (2005). The position of the Hymenoptera within the Holometabola as inferred from the mitochondrial genome of Perga condei (Hymenoptera: Symphyta: Pergidae). Molecular Phylogenetics and Evolution, 34, 469-479. http://dx.doi.org/10.1016/j.ympev.2004.11.005

Corbert, G. B., \& Hill, J. E. (1980). A World List of Mammalian Species. Ithaca: Cornell University Press.

Fisher-Reid, M. C., \& Wiens, J. J. (2011). What are the consequences of combining nuclear and mitochondrial data for phylogenetic analysis? Lessons from Plethodon salamanders and 13 other vertebrate clades. BMC Evolutionary Biology, 11, 300. http://dx.doi.org/10.1186/1471-2148-11-300

Flerov, K. K. (1952). Fauna of USSR mammals. Moscow: Academy of Science of the USSR. Musk deer and deer.

Gatesy, J., Matthee, C., DeSalle, R., \& Hayashi, C., (2002). Resolution of a supertree/supermatrix paradox. Systematic Biology, 51, 652-664. http://dx.doi.org/10.1080/10635150290102311

Gatesy, J., Milinkovitch, M., Waddell, V., \& Stanhope, M. (1999). Stability of cladistic relationships between Cetacea and higher-level artiodactyl taxa. Systematic Biology, 48, 6-20. http://dx.doi.org/10.1080/106351599260409

Guha, S., Goyal, S. P., \& Kashyap, V. K. (2007). Molecular phylogeny of musk deer: a genomic view with mitochondrial 16S rRNA and cytochrome b gene. Molecular Phylogenetics and Evolution, 42, 585-597. http://dx.doi.org/10.1016/j.ympev.2006.06.020

Hassanin, A., Delsuc, F., Ropiquet, A., Hammere, C., Vuuren, B. J., Matthee, C., .. Couloux, A. (2012). Pattern and timing of diversification of Cetartiodactyla(Mammalia, Laurasiatheria), as revealed by a comprehensive analysis of mitochondrial genomes. Comptes Rendus Biologies, 335, 32-50. http://dx.doi.org/10.1016/j.crvi.2011.11.002

Janis, C. M., \& Scott, K. M. (1988). The phylogeny of the Ruminantia (Artiodactyla, Mammalia). In M. J. Benton (Ed.), The phylogeny and classification of the tetrapods (pp. 273-282). Oxford (UK): Clarendon Press.

Krzywinski, J., Grushko, O. G., \& Besansky, N. J. (2006). Analysis of the complete mitochondrial DNA from Anopheles funestus: An improved dipteran mitochondrial genome annotation and a temporal dimension of mosquito evolution. Molecular Phylogenetics and Evolution, 39, 417-423. http://dx.doi.org/10.1016/j.ympev.2006.01.006

Leinders, J. J. M., \& Heintz, E. (1980). The configuration of the lacrimal orifices in pecorans and tragulids (Artiodactyla, Mammalia) and its significance for the distinction between Bovidae and Cervidae. Beaufortia, 30, 155-162.

Li, M., Sheng, H. L., Tamate, H., Masuda, R., Nagata, J., \& Ohtaishi, N. (1998). mtDNA difference and molecular phylogeny among musk deer, chinese water deer, muntjak and deer. Acta Theriol Sin., 18, 184-191.

Matthee, C. A., Burzlaff, J. D., Taylor, J. F., \& Davis, S. K. (2001). Mining the mammalian genome for Artiodactyl systematics. Systematic Biology, 50, 367-390. http://dx.doi.org/10.1080/10635150119683

Métais, G., Chaimanee, Y., Jaeger, J. J., \& Ducrocq, S. (2007). Eocene bunoselenodont Artiodactyla from southern Thailand and the early evolution of Ruminantia in South Asia. Naturwissenschaften, 94, 493-498. http://dx.doi.org/10.1007/s00114-007-0218-2

Montgelard, C., Catzeflis, F. M., \& Douzery, E. (1997). Phylogenetic relationships of artiodactyls and cetaceans as deduced from the comparison of cytochrome $\mathrm{b}$ and $12 \mathrm{~S}$ rRNA mitochondrial sequences. Molecular Biology and Evolution, 14, 550-559.

Murphy, D. A., Stein, J. A., Schlenger, W., \& Maibach, E. (2001). Conceptualizing the multidimensional nature of self-efficacy: assessment of situational context and level of behavioral challenge to maintain safer sex. Health Psychology, 20, 281-290. http://dx.doi.org/10.1037/0278-6133.20.4.281

Nikaido, M., Kawai, K., Gao, Y., Harada, M., Tomita, S., Okada, N., \& Hasegawa, M. (2001). Maximum Likelihood analysis of the complete mitochondrial genomes of eutherians and a reevaluation of the phylogeny of bats and insectivores. Journal of Molecular Evolution, 53, 508-516. http://dx.doi.org/10.1007/s002390010241 
Nikaido, M., Rooney, A. P., \& Okada, N. (1999). Phylogenetic relationships among cetartiodactyls based on insertions of short and long interpersed elements: hippopotamuses are the closest extant relatives of whales. Proceedings of the National Academy of Sciences of the United States of America, 96, 10261-10266. http://dx.doi.org/10.1073/pnas.96.18.10261

O'Leary, M. A., \& Gatesy, J. (2008). Impact of increased character sampling on the phylogeny of Cetartiodactyla (Mammalia): combined analysis including fossils. Cladistics-the International Journal of the Willi Hennig Society, 24, 397-442. http://dx.doi.org/10.1111/j.1096-0031.2007.00187.x

Peng, H. Y., Liu, S. C., Zeng, B., Zou, F. D., Zhang, X. Y., \& Yue, B. S. (2009). The complete mitochondrial genome and phylogenetic analysis of forest musk deer (Moschus berezovskii). Journal of Natural History, 43, 1219-1227. http://dx.doi.org/10.1080/00222930902767458

Posada, D., \& Crandall, K. A. (1998). Modeltest: Testing the model of DNA substitution. Bioinformatics, 4, 817-818. http://dx.doi.org/10.1093/bioinformatics/14.9.817

Price, S. A., Bininda-Emonds, O. R. P., \& Gittleman, J. L. (2005). A complete phylogeny of the whales, dolphins and even-toed hoofed mammals (Cetartiodactyla). Biological Reviews of the Cambridge Philosophical Society, 80, 445-473. http://dx.doi.org/10.1017/S1464793105006743

Ragan, M. A. (1992). Phylogenetic inference based on matrix representation of trees. Molecular Phylogenetics and Evolution, 1, 53-58. http://dx.doi.org/10.1016/1055-7903(92)90035-F

Rambaut, A., \& Drummond, A. (2005). Tracer v1.3: MCMC trace analysis tool. Institute of Evolutionary Biology, University of Edinburgh.

Ronquist, F., \& Huelsenbeck, J. P. (2003). MRBAYES 3: Bayesian phylogenetic inference under mixed models. Bioinformatics, 19, 1572-1574. http://dx.doi.org/10.1093/bioinformatics/btg180

Shimodaira, H. (2002). An approximately unbiased test of phylogenetic tree selection. Systems Biology, 51, 492-508. http://dx.doi.org/10.1080/10635150290069913

Simpson, G. G. (1945). The principles of classification and a classification of mammals. Bulletin of the American Museum of Natural History, 85, 1-350.

Stamatakis, A., Hoover, P., \& Rougemont, J. (2008). A rapid bootstrap algorithm for the RAxMLWeb-servers. Systems Biology, 75, 758-771. http://dx.doi.org/10.1080/10635150802429642

Su, B., Wang, Y. X., \& Wang, Q. S. (2001). Mitochondrial DNA sequences imply Anhui musk deer a valid species in genus Moschus. Zoological Research, 22, 169-173.

Thewissen, J. G., \& Hussain, S. T. (1993). Origin of underwater hearing in whales. Nature, 361, 444-445. http://dx.doi.org/10.1038/361444a0

Thewissen, J. G., Williams, E. M., Roe, L. J., \& Hussain, S. T. (2001). Skeletons of terrestrial cetaceans and the relationship of whales to artiodactyls. Nature, 413, 277-281.

Tompson, J. D., Gibson, T. J., Plewniak, F., Jeanmougin, F., \& Higgins, D. J. (1997). The Clustal X windows interface: flexible strategies for multiple sequence alignment aided by quality analysis tools. Nucleic Acids Research, 25, 4876-4882. http://dx.doi.org/10.1093/nar/25.24.4876

Ursing, B. M., Slack, K. E., \& Arnason, U. (2000). Subordinal artiodactyl relationships in the light of phylogenetic analysis of 12 mitochondrial protein-coding genes. Zoologica Scripta, 29, 83-88. http://dx.doi.org/10.1046/j.1463-6409.2000.00037.x

Wada, K., Nishibori, M., \& Yokohama, M. (2007). The complete nucleotide sequence of mitochondrial genome in Japanese Sika deer (Cervus nippon), and a phylogenetic analysis between Cervidae and Bovidae. Small Ruminant Research, 69, 46-54. http://dx.doi.org/10.1016/j.smallrumres.2005.12.002

Yang, C. Z., Zhang, X. Y., Guo, Y. S., Gao, Y. M., Xiong, Y. Q., Wang, L. B., ... Yue, B. S. (2012). The complete mitochondrial genome of the Chinese Sika deer (Cervus nippon Temminck, 1838), and Phylogenetic analysis among Cervidae, Moschidae and Bovidae. Journal of Natural History, 46, 1747-1759. http://dx.doi.org/10.1080/00222933.2012.693959

Zhou, X. M., Xu, S. X., Yang, Y. X., Zhou, K. Y., \& Yang, G. (2011). Phylogenomic analyses and improved resolution of Cetartiodactyla. Molecular Phylogenetics and Evolution, 61, 255-264. http://dx.doi.org/10.1016/j.ympev.2011.02.009 